\title{
Evaluación de la administración rutinaria de antibióticos en lactantes con infecciones respiratorias agudas bajas
}

\author{
Dra. Rossana Lambertini J. 1: Dra. Silvia Núñez G. 1: Dr. Arturo Gallo B. ${ }^{2}$ : \\ Dr. Iván Casas O. 1 ; Dr. José Domingo Arce V. 3 ; Dr. Hernán Taboada L. 4; \\ EU. Enriqueta Galleguillos 0.5 : EU. Aurora Jeralde V.5 \\ Evaluation of routine administration of antibiotics \\ to infants with lower respiratory infections
}

\begin{abstract}
Routine administration of antibiotics in the treatment of acute lower respiratory infections in infants was evaluated in a open randomised prospective trial. Sixty one infants between the age of 1 month and 2 years were allocated to one of two treatment groups. Group A patients were treated with antibiotics but those in Group B were not. Antibiotics were not given to this patients before hospital admission. There were no differences in the duration of the acute disease, the frecuency of fever relapse and pulmonary complications. Four patients from Group B were subsequently treated with antibiotics, all them had radiologic evidence of bronchopneumonia. These results do not support the routine use of antibiotics in infants admitted to hospital with acute lower respiratory infections, except in those with radiologic evidence of bronchopneumonia.

(Key words: Acute lower respiratory infections, routine antibiotic therapy, treatment evaluation).
\end{abstract}

Las infecciones respiratorias agudas constituyen entre 50 y $60 \%$ de las consultas pediátricas ambulatorias y una de las principales causas de

1. Becađo. Pediatría, Universidad Católica de Chile.

2. Médico. Servicio de Pediatría, Hospital Sotero del Río.

3. Médico radiólogo.

4. Hematólogo Infantil, Hospital Sótero del Rio.

5. Enfermeras Servicio de Pediatría, Hospital Sótero đel Río. morbimortalidad en el mundo ${ }^{4-6}$. En los paises menos desarrollados la mortalidad por estas infecciones es 5 a 25 veces mayor que en los paises industrializados ${ }^{1}$.

Los agentes etiológicos varían con la edad del paciente y el nivel socioeconómico. En los países desarrollados las causas preponderantes de las neumopatjas agudas en el lactante serían virales y menus del $10 \%$ por agentes bacterianos ${ }^{2,3,7}$. Sin embargo estos últimos parecen ser relativamente 
más frecuentes en los paises en desarrollo $4,1,6$ En nuestro pais este problema no ha sido evaluado, sin embargo es la impresión de muchos que nuestra realidad pareciera ser intermedia. Debido a las dificultades que existen para identificar la etiologia de las infecciones respiratorias bajas, en estos casos se recurre, con frecuencia, al uso indiscriminado de antibióticos: este estudio se propone evaluar algunos criterios clínicos y de laboratorio que pudiesen servir para su empleo más racional en lactantes.

\section{PACIENTES Y METODOS}

Se realizó un estudio prospectivo de 61 lactantes de 1 mes a 1 año 11 meses bospitalizados en el servicio de pediatría del hospital Sótero del Rio; en el período comprendido entre mayo y septiembre de 1985 con diagnósticos presuntivos de neumopatía aguda, caracterizada por la combinación variable de los siguientes hallazgos: fjebre, tos, taquipnea, quejido, aleteo nasil, dificultad respiratoria, auscultación de ruidos respiratorios anormales (roncus, estertores, broncofonía, respiración soplante) o radiología anormal o anbas. Los pacientes fuemon asignados al azar en dos grupos aleatorios según el orden de hospitalización. El grupo A recibió tratamiento antibiótico (penicilina sódica $100.000 \mathrm{U} \times \mathrm{kg} \times$ día más gentamicina $7 \mathrm{mg} \times \mathrm{kg} \times$ día en el menor de 3 meses $x$ 10 dias y pericilina sódica en igual dosis en lactantes mayores de 3 meses durante 7 días. El grupo B no recibió antibióticos. El tratamiento común para ambos grupos consistió en oxígeno, kine sioterapia respiratoria y medidas.de enfermería.

Los requisitos de ingreso al estudio fueron: ausencia de afecciones pulmonares ćonicas o cardiovasculares; по haber recibido antibióticos en los 5 dias previos al ingreso.

Al ingreso se realizaron: hemograma, velocidad de sedimentación globular (VHS), gases ar teriales y radiografías de tórax. Las imśgenes radiológicas fueron clasificadas por un rafiólogo pediátrico en bronconeumonia: sombras alveolares algodonosas con tendencia a confluir, ubicadas en uno o varios lóbulos, sin distribución segmentaria; neumonja lobar: imágenes alveolares confluentes que producen clara condensación con broncograma aéreo y siguen una distribución segmentaria o comprometen todo un lóbulo; peribronquitis: imágenes intersticiales de distribución difusa en el parénquima pulmonar; hiperinsuflación: diafragmas planos, visualización de más de 9 espacios intercostales y aumento de! espacio retroesternal.

Se evaluaron los siguientes paránetros: duración de la fiebre, requerimientos de oxígeno, tiempo de normalización de la frecuencia respiratoria (FR) y cardiaca (FC) y duración de la hospicalización. Como límite de FR y FC normales se consideró convencionalmente 40 y $140 \mathrm{x}$ ' respectivamente.

Se consideró fracaso del tratamiento la persistencia de astenia, adinamia y temperatura elevada después de 72 horas del ingreso o empecramiento de los síntomas que causaron el ingreso.

El análisis estadístico se realizó en base al "Minitab" elaborado por Pensyluania State University, 1981, y adaptado pot el departamento de estadistica de la Universidad Católica de Chile -Computador Dcc 10-, mediante las pruebas de Student y Chircuadrado.

\section{RESULTADOS}

La Tabla 1 muestra las caracteristicas clínicas at ingreso de los lactantes asignados a los dos grupos. No encontramos diferencias estadisticamente significativas en la edad, peso, duración de los sintomas antes de la hospitalización, temperatura, FC, ni requerimientos dc oxigeno. La frecuencia respiratoria fue significativamente mayor en los pacientes destinados a tratamiento con antibióticos.

Los resultados de los exámenes de laboratorio en el momento del ingreso fueron similares en ambos grupos para la VHS y los hallazgos del hemograma salvo en las plaquetas, que cualitativamente mostraron mayores acúmulos en el grupo A. (Tabla 2).

Tabla 1.

Características clínicas al ingreso de 61 lactantes con infección respiratoria aguda baja

\begin{tabular}{lccc}
\hline & $\begin{array}{c}\text { Grupo A } \\
\mathrm{N}=30\end{array}$ & $\begin{array}{c}\text { Grupo B } \\
\mathrm{N}=31\end{array}$ & $\mathrm{P}$ \\
$\mathrm{X} \pm \mathrm{D} . \mathrm{E}$. & $\mathrm{X} \pm \mathrm{D} . \mathrm{E}$. & \\
\hline Edad (días) & $115 \pm 94$ & $139,03 \pm 139$ & N.S. \\
Peso (Kg.) & $5,3 \pm 1,8$ & $5,6 \pm 29$ & N.S. \\
Síntomas previos (días) & $4,7 \pm 3$ & $5,6 \pm 49$ & N.S. \\
Temperatura ('C) & $37,2 \pm 0,6$ & $37,3 \pm 0,8$ & N.S. \\
Frecuencia respiratoria & $56 \pm 9,8$ & $50,2 \pm 8,4$ & $<0,05$ \\
Frecuencia cardíaca & $145 \pm 11$ & $142 \pm 10$ & N.S. \\
Fracción inspirada oxígeno & $29,5 \pm 7,3$ & $29,3 \pm 6,2$ & N.S. \\
\hline \hline
\end{tabular}

Grupo A : Con tratamiento antibiótico

Grupo B : Sin tratamiento antibiótico

$\mathrm{P} \quad$ : Significación estadística

N.S. : No Significativo 
Tabla 2.

Caracteristicas de laboratorio al ingreso de 61 tactantes con infección respiratoria aguda baja

\begin{tabular}{|c|c|c|c|}
\hline & $\begin{array}{c}\text { Grupo A } \\
N=30 \\
\bar{X} \pm D . E\end{array}$ & $\begin{array}{c}\text { Grupo B } \\
N=31 \\
X \pm D . E .\end{array}$ & $\mathbf{P}$ \\
\hline Hematocrito & $33: 2 \pm 5,45$ & $34,8 \pm 7,26$ & N.S. \\
\hline Leucocitos $x \mathrm{~mm}^{3}$ & $8513 \pm 3.854$ & $8.751 \pm 3.160$ & N.S. \\
\hline 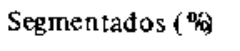 & $35,8 \pm 16$ & $40,5 \pm 16$ & N.S. \\
\hline Baciliformes (\%) & $2,88 \pm 4,28$ & $0,85 \pm 1,4$ & N.S. \\
\hline Linfocitos (\%) & $49,9 \pm 15,5$ & $47,3 \pm 13$ & N.S. \\
\hline VHS $(\mathrm{mm} / \mathrm{Hr})$ & $23,4 \pm 22$ & $19 \pm 23$ & N.S. \\
\hline Plaquetas $\left(m m^{3}\right)$ & $>$ acumulos & $<$ acumnulos & $<0.05$ \\
\hline
\end{tabular}

Grupo A : Con tratamiento antibiotico.

Grupo B : Sin tratamiento antibiótico.

$P \quad$ : Significación estadistica.

N.S. : No significativo.

Tabla 3.

Diagnóstico radiológico de 61 lactantes con infección respiratoria aguda baja

\begin{tabular}{lcccc}
\hline Imagen radiológica & $\begin{array}{c}\text { Total } \\
\mathrm{N}=61\end{array}$ & $\begin{array}{c}\text { Grupo A } \\
\mathrm{N}=30\end{array}$ & $\begin{array}{c}\text { Grupo B } \\
\mathrm{N}=31\end{array}$ & $\mathrm{P}$ \\
Bronconeumonia & 15 & 9 & 6 & N.S. \\
Hiperinsuflación & 14 & 6 & 8 & N.S. \\
Neumonitis & 25 & 9 & 16 & N.S. \\
Normal & 7 & 6 & 1 & - \\
Atelectasias \# & 17 & 7 & 1 & N.S. \\
\hline \hline
\end{tabular}

\#Atelectasias asociadas a otra imagen radiológica.

$\begin{array}{ll}\text { Grupo A } & \text { : Con tratamiento antibiótico. } \\ \text { Grupo B } & \text { : Sin tratamiento antibiótico. } \\ \text { P } & \text { : Significación estadistica. } \\ \text { N.S. } & \text { : No significativa. }\end{array}$

La distribución de los diterentes patrones radiológicos, antes definidos, fue similar en ambos grupos. Las atelectasias se distribuyeron de modo uniforme asociadas a otra imagen radiológica en los dos grupos de pacientes (Tabla 3 ).

No se encontraron diferencias en la duración de la fiebre, los requerimientos de oxigeno, el tiempo de normalización de FR y FC, pero la duración de la hospitalización fue mayor $(p<0,05)$ en el grupo A. (Tabla 4$)$.

En 4 pacientes fracasó el tratanicntu, todos eran lactantes asignados al grupo B y tenian patrón radiológico de bronconeumonia. En uno se observó progresión de las imágenes radiológi- cas, en otro, persistencia de astenia y adinamia, aumento de temperatura $y$ de requerimientos de oxigeno al quinto día de hospitalización después de un período de aparente mejoría y los dos últimos no mostraron mejoría después de transcurridas 72 horas del ingreso.

No ocurrieron complicaciones graves ni muertes en esta serie.

\section{DISCUSION}

Los dos grupos de pacientes en estudio fueron comparables desde el punto de vista clínico, de laboratorio y radiológico, excepto por la diferen- 
Tabla 4.

Evolución clínica de 61 lactantes con ira baja

\begin{tabular}{|c|c|c|c|}
\hline · & $\begin{array}{l}\text { Grupo A } \\
(N=30) \\
\bar{X} \pm D . E\end{array}$ & $\begin{array}{l}\text { Grupo B } \\
(\mathrm{N}=31) \\
\mathrm{X} \pm \mathrm{D} . \mathrm{E} .\end{array}$ & $\mathbf{P}$ \\
\hline Duración fiebre (días) & $1,35 \pm 1,1$ & $1,50 \pm 1,6$ & N.S. \\
\hline Duración hospitalización (días) & $7,2 \quad \pm 2$ & $6 \pm 2,3$ & $\mathrm{P}<0,05$ \\
\hline Duración requerimientos $\theta_{2}(\mathrm{~F} / \mathrm{O})$ & $3 \pm 2,6$ & $2,90 \pm 2,6$ & N.S. \\
\hline $\begin{array}{l}\text { Tiempo normalización frecuencia } \\
\text { respiratoria (dias) }\end{array}$ & $3,2 \pm 2,4$ & $2,9 \pm 1,84$ & N.S. \\
\hline $\begin{array}{l}\text { Tiempo normalización frecuencia } \\
\text { ardíaca (días) }\end{array}$ & $1,4 \pm 1,5$ & $1,03 \pm 1,35$ & N.S. \\
\hline
\end{tabular}

$\begin{array}{ll}\text { Grupo A } & \text { : Con tratamiento antibiótico. } \\ \text { Grupo B } & \text { : Sin tratamiento antibiótico. } \\ \mathrm{P} & \text { : Significación estadistica. } \\ \text { N.S. } & \text { : No significativos, }\end{array}$

cia observada en relación a FR, que no nos parece que tenga traducción clínica importante: El hallazgo de aumento de acúmulos plaquetarios es inespccífico y se asocia a un gran número de condiciones patológicas entre las cuales se mencionan las infecciones bacterianas o virales ${ }^{5}$.

La hospitaljzación fue más larga en el grupo A, lo que es explicable por la necesidad de completar su tratamiento en el periodo preestablecido.

Sólo $25 \%$ de los lactantes, que ingresaron con diagnóstico presuntivo de neumopatía aguda, tenían realmente imágenes radiológicas compatibles cun bronconeumonia. Siete pacientes tenían radiología normal, entre ellos 6 recibieron tratamiento antibiótico. Más del $50 \%$ de los pacientes tenían signos radiológicos de hiperinsuflación e imágenes intersticiales, que evolucionaron de manera similar en ambos grupos a semejanza de otras experjencias y sugiriendo que su etiología es viral ${ }^{8}$. Los cuatro fracasos pertenecían al grupo B y tenían imágenes radiológicas de bronconeumonia.

Si bien nuestra muestra fue seleccionada, ya que muchos lactantes hospitalizados no pudieron ingresar al estudio por haber recibido tratamiento previo con antibióticos, algunas conclusiones parecen válidas: la evolución semejante de ambos grupos sugierc etiologia no bacteriana en un número importante de pacientes; el patrón tadiológico de bronconeumonia evolucionó mal sin antibióticos: aunque sabemos que existen bronconeumonias virales, estas imágenes radiológicas en nuestros casos parecieran estar asociadas con infecciones bacterianas y resultaron ser el único elemento indicador para el uso precoz de antibióticos en esta serie. En los lactantes con signos radiológicos de hiperinsuflación e imágenes de tipo intersticial, con o sin atelectasias, la evolu. ción fue similar con o sin antibióticos, lo que justificaria observarlos por un tiempo razonable antes de tratarlos con dichas drogas. No se encontraron en los hemogramas parametros que permitiesen predecir la evolución clínica ni que guardasen relación con las imágenes radiológicas.

\section{RESUMEN}

Se comparó la evolución clínica de dos grupos de lactantes hospitalizados por neumopatía aguda, unos tratados con antibióticos y los otros no. El tamafio de cada grupo fue de 30 y 31 niños respectivamente sin diferencias de edad, temperstura, signos radiológicos, necesidad de oxígeno, VHS y fórmula leucocitaria. La evolución de ambos grupos fue similar. Cuatro lactantes del grupo sin antibióticos debieron ser retirados por máa evolución; todos tenían en común un patrón radiológico de bronconeumonia. Se concluye que en nuestro medio, los signos radiológicos de bronconeumonia sugerirían infecciones bacterianas, debiendo en estos casos usarse precozmente antibióticos. Otros hallazgos radiológicos o signos clinicos dudosos justificarían un período de observación de la evolución antes de tomar otras decisiones terapeuticas. Las características del hemograma no se relacionaron con la cvolución clínica ni con las imágenes radiológicas.

\section{REFERENCIAS}

1. Organización Panamericama de la Sahud. Infecciones Respiratorias Agudas en las Américas. Boletín Epidemiológico l: 1, 1980 . 
2. Paisley, J: Pathogens associated with acute lower respiratory tract infection iл young children. Pediatr Infect Dis 3: 14, 1984.

3. Long, $S$.: Treatment of Acute Pneumonia in Infants and children. Pediatr Clin North Am 30: 297. 1983.

4. Shoun, F: Etiology of Pneumonia in children in Garoka Hospital Papua New Guinea. Lancet Il: 537. 1984.

5. Addrego. J.: Thrombocy tosis in infants and children. J Pediatr 85: 805, 1974.
6. Smith, C, Overoll, J.: Clinicat and epidemiologic ches to the diagnosis of respiratory infections. Radiol Clin North Am 11: 261, 1973.

7. Jacobs, J., Peacok, D., Corner, B.: Respiratory syncytial and other viruses associated with respiratory disease in infants. Lancet $1: 870,1971$.

8. Osborne, D.: Radiologic appearance of viral disease of the lower respiratory tract in infants and children. Am J Roentgenol 130: 29, 1978. 